\title{
What is the Role of Kinesiophobia and Pain Catastrophizing in Outcomes After Hip Arthroscopy for Femoroacetabular Impingement Syndrome?
}

\author{
Ian M. Clapp, B.A., Benedict U. Nwachukwu, M.D., M.B.A., Edward C. Beck, M.D., M.P.H., \\ Jonathan P. Rasio, B.S., Thomas Alter, M.S., Bradley Allison, P.T., D.P.T., O.C.S., and \\ Shane J. Nho, M.D., M.S.
}

\begin{abstract}
Purpose: To (1) investigate trends in kinesiophobia and pain catastrophizing after hip arthroscopy for femoroacetabular impingement syndrome (FAIS), and (2) determine whether kinesiophobia and pain catastrophizing scores are associated with achieving minimal clinically important difference (MCID) for any of the hip-specific patient-reported outcome questionnaires. Methods: Patients undergoing primary hip arthroscopy for treatment of FAIS between December 2016 and March 2017 were prospectively enrolled. Patients received the Tampa Scale of Kinesiophoibia-1 1 (TSK-1 1) and Pain Catastrophizing Scale (PCS) questionnaires preoperatively, 6 months, and 1 year postoperatively. They also received the hip-specific patient-reported outcome questionnaires (Hip Outcome Score Activities of Daily Living and Sport-Specific subscales, modified Harris Hip Score, and International Hip Outcome Tool-12), as well as visual analog scale for satisfaction and pain preoperatively and 1-year postoperatively. The threshold for achieving MCID was determined for each hip outcome tool, and patients achieving MCID were compared with those who did not. Results: A total of 85 (80.2\%) patients (mean age: $33.7 \pm 12.4$ years; female: $75.3 \%)$ were included in the final analysis. At l-year follow-up, there was a significant reduction in TSK-1 1 scores $(26.22 \pm 5.99$ to $18.70 \pm 6.49 ; P<.001)$ and PCS scores $(17.81 \pm 10.13$ to $4.77 \pm 7.57 ; P<.001)$ when compared with preoperative scores. 1-year PCS scores were significantly lower in patients achieving MCID compared with patients failing to achieve MCID (3.2 \pm 4.4 vs $10.8 \pm 15.2 ; P=.006$ ). There were no significant differences in TSK-11 scores between those achieving and not achieving MCID. Conclusions: Patient kinesiophobia and pain catastrophizing both show significant improvements 1 year after undergoing hip arthroscopy for FAIS. However, pain catastrophizing scores at 1 year are significantly greater in patients not achieving MCID, whereas no association was identified between kinesiophobia and likelihood for MCID achievement. This suggests PCS may be a more useful tool than TSK-11 during postoperative rehabilitation for identifying patients at risk for not achieving MCID. Level of Evidence: Level II, prospective case series
\end{abstract}

$\mathbf{O}$ ver the past decade, hip arthroscopy has become a routine procedure for the surgical treatment of femoroacetabular impingement syndrome (FAIS), with favorable outcomes and high success rates at short-, mid, and long-term follow-up. ${ }^{1-9}$ Yet, as with all orthopaedic procedures, rate of recovery and outcomes are highly

From the Department of Orthopedic Surgery, Rush University Medical Center, Chicago, Illinois (I.M.C., B.U.N., J.P.R., T.A., B.A., S.J.N.); and Department of Orthopedic Surgery, Wake Forest Baptist Health, WinstonSalem, North Carolina (E.C.B.), U.S.A.

The authors report the following potential conflicts of interest or sources of funding: S.J.N. reports nonfinancial support from Allosource, other from American Journal of Orthopedics, other from American Orthopaedic Society for Sports Medicine, nonfinancial support from Arthrex, Inc, other from Arthroscopy Association of North America, non-financial support from Athletico, non-financial support from DJ Orthopaedics, nonfinancial support from Linvatec, nonfinancial support from Miomed, personal fees from Ossur, nonfinancial support from Smith $\theta$ Nephew, personal fees and nonfinancial support from Springer, and nonfinancial support from Stryker, outside the influenced by patient-specific factors, including age, sex, body habitus, and arthritic changes. ${ }^{10,11}$ Increasing evidence has demonstrated that outcomes of orthopaedic procedures also depend on patient psychological traits, which can affect compliance, rehabilitation effort, and pain perception. ${ }^{12,13}$ It recently has been shown that

submitted work. Full ICMJE author disclosure forms are available for this article online, as supplementary material.

Received August 29, 2019; accepted December 12, 2019.

Address correspondence to Shane J. Nho, M.D., M.S., Department of Orthopedic Surgery, Rush University Medical Center, 1611 West Harrison St., Suite 300,Chicago, IL 60612.E-mail:nho.research@rushortho.com

(C) 2020 THE AUTHORS. Published by Elsevier Inc. on behalf of the Arthroscopy Association of North America. This is an open access article under the CC BY-NC-ND license (http://creativecommons.org/licenses/by-nc-nd/4.0/). 2666-061X/191059

https://doi.org/10.1016/j.asmr.2019.12.001 
psychological factors such as depression and distress are predictors of lower preoperative patient-reported outcome scores, chronic postoperative pain, and poor outcomes following hip arthroscopy. ${ }^{14-18}$ However, the effects of specific components of psychological distress such as kinesiophobia and pain catastrophizing have not been widely studied in the hip arthroscopy literature.

Patient psychological traits influence interpretation of pain and adjustment to pain, which may have more effect on patient outcomes and recovery than initially observed. ${ }^{19,20}$ According to the fear avoidance model of musculoskeletal pain, when a patient experiences recurrent pain, they may have an exaggerated or inappropriate response to that pain, known as pain catastrophizing, which may lead to an excessive fear of physical movement arising from the belief of susceptibility to injury, known as kinesiophobia. ${ }^{21}$ This can often lead to avoidance of physical activity, which negatively affects patient performance in postoperative therapy and recovery. ${ }^{20}$

Pain catastrophizing can be objectively measured using the Pain Catastrophizing Scale (PCS), with greater scores indicating greater catastrophizing, ${ }^{22}$ whereas The Tampa Scale for Kinesiophobia (TSK) or the shorter validated Tampa Scale for Kinesiophobia-11 (TSK-11) can objectively quantify kinesiophobia levels, with greater scores indicating a greater degree of kinesiophobia. ${ }^{23}$ Greater levels of pain catastrophizing have been shown to negatively influence the outcome of total knee arthroplasty (TKA) $)^{24,25}$ and spine surgery for lumbar stenosis. $^{26}$ Greater levels of kinesiophobia also have been shown to have a negative effect on the outcome of TKA $^{19,24,27}$ as well as spine surgery for degenerative diseases of the cervical and lumbar spine. ${ }^{28}$ It has been shown that kinesiophobia also impacts anterior cruciate ligament reconstruction, with greater postoperative TSK and TSK-11 scores correlated with worse self-reported outcomes and return to activities following surgery. ${ }^{29,30}$ Given that hip arthroscopy requires months of rehabilitation to achieve a successful outcome and that kinesiophobia and pain catastrophizing affect the outcomes and rehabilitation of other orthopaedic procedures, it is plausible that patients with these 2 psychological factors may not do as well during rehabilitation and thus have poorer surgical outcome after hip arthroscopy. ${ }^{13,24,28,31,32}$

Although the effects of pain catastrophizing and kinesiophobia on patient outcomes are well established in the TKA, spine, and anterior cruciate ligament reconstruction literature, the effects of these psychological traits are not well described in the treatment of FAIS. The purposes of this study are to 1) investigate trends in kinesiophobia and pain catastrophizing after hip arthroscopy for FAIS, and 2) determine whether kinesiophobia and pain catastrophizing scores are associated with achieving any minimal clinically important difference (MCID) for any of the hip-specific patient-reported outcome questionnaires. We hypothesized that TSK and PCS scores would be lower, whereas hip specific patient-reported outcome measures (PROMs) would improve at 1-year follow up. In addition, we hypothesized that TSK and PCS scores would be significantly greater in patients failing to achieve MCID at 1-year follow-up.

\section{Methods}

\section{Patient Selection}

Following institutional review board approval (12022108-IRB01-CR06 Hip injury and arthritis repository), consecutive patients undergoing primary hip arthroscopy between December 1, 2016, and March 1, 2017, for the treatment of FAIS by a fellowship-trained surgeon (S.J.N.) were prospectively enrolled in the

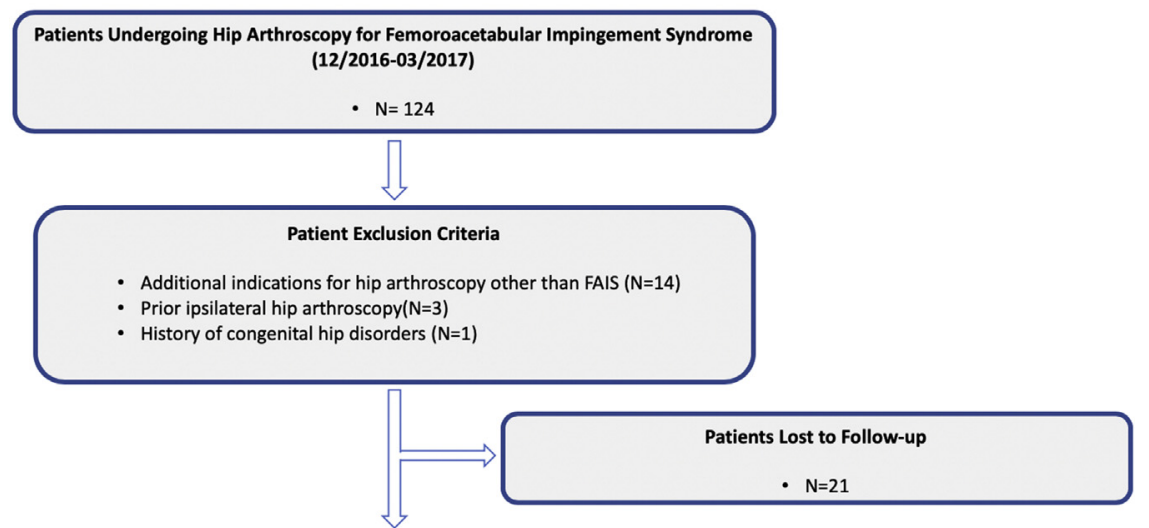

Patients Meeting Inclusion Criteria with Minimum 5-year Follow up - $\mathrm{N}=85$
Fig 1. Flow chart indicating patients who were dropped due to exclusion criteria and those who met inclusion criteria and included in the final analysis. (FAIS, femoroacetabular impingement syndrome.) 
Table 1. Patient Demographics

\begin{tabular}{lc}
\hline & Mean \pm Standard Deviation \\
\hline Age, y & $33.7 \pm 12.4$ \\
Sex & \\
Male & $21(24.7 \%)$ \\
Female & $64(75.3 \%)$ \\
Body mass index & $24.4 \pm 3.9$ \\
\hline
\end{tabular}

study. Inclusion criteria consisted of clinical and radiographic diagnosis of symptomatic FAIS as previously described and assessed by the senior author, ${ }^{33}$ failure of nonoperative management (physical therapy, activity modification, oral anti-inflammatory drugs, and for some patients fluoroscopically-guided intra-articular cortisone injection). Exclusion criteria consisted of hip arthroscopy for an indication other than FAIS, previous history of ipsilateral or contralateral hip surgery, undergoing contralateral hip arthroscopy during study enrollment and follow-up, signs of osteoarthritis (Tönnis grade $>1$ ), hip dysplasia (lateral center edge angle $<20^{\circ}$ ), ${ }^{34}$ or a history of pediatric hip disorders (slipped capital femoral epiphysis, avascular necrosis, developmental dysplasia of the hip, etc.).

\section{Surgical Technique}

All hip arthroscopies were performed by a single surgeon at a high-volume academic hospital using a technique that has been well-described in the literature. $^{35-37}$ In brief, standard anterolateral and midanterior portals were established under traction with the aid of fluoroscopic guidance. A 2-cm interportal capsulotomy was created and pathology was addressed in the central compartment. Depending on intraarticular findings, central compartment procedures included acetabuloplasty and labral repair. Next, after traction release, the interportal capsulotomy was extended inferiorly at the midpoint to create a T-capsulotomy for access to the peripheral compartment. The medial and lateral leaflets of the iliofemoral ligament were retracted with sutures for increased visualization. Cam morphology was meticulously resected until an adequate femoral head-neck offset was achieved. Upon completion, a dynamic examination of the operative leg was performed to confirm an appropriate resolution of impingement. The capsule was then repaired using a suture shuttling system and plication was performed depending on degree of capsular laxity. ${ }^{38}$

\section{Postoperative Rehabilitation}

Rehabilitation started on postoperative day 1 for all patients as previously described and did not differ from therapy indicated for primary FAIS cases. ${ }^{7,31}$ Patients went through a 4-phase rehabilitation protocol that lasted an average of 16 to 18 weeks. To summarize, rehabilitation phase 1 prioritized joint protection and soft-tissue mobilization techniques. Patients advanced to phase 2 if they demonstrated full weight-bearing capabilities. Phase 2 concentrated on normal gait maintenance, full range of motion restoration, improvement of neuromuscular control, and maintenance of pelvic and core stability. Phase 3 included single-leg squats and strengthening, soft-tissue and joint mobilization, and cardiovascular fitness. Phase 4 emphasized return to preinjury level of sports participation. Patients were cleared to return to sports if they were able to participate in sports without pain, had full dynamic functional control, and passed all return to sports tests.

\section{Functional Outcome Evaluation}

All patients were evaluated for at least a minimum of 1 year from initial surgical intervention. Patients were assigned the TSK-11 and the PCS questionnaires at the preoperative visit, 6-month, and 1-year postoperative visits. The scores of the TSK-11 range from 11 to 44, with greater scores signifying greater kinesiophobia. ${ }^{23}$ The PCS is a 13-item questionnaire with scores ranging from 0 to 52 , with greater scores indicating greater levels of catastrophizing. ${ }^{22}$ Patients also received the Hip Outcome Score Activities of Daily Living (HOS-ADL) ${ }^{39}$ and SportSpecific (HOS-SS) subscales, ${ }^{40}$ modified Harris Hip Score (mHHS), ${ }^{41}$ International Hip Outcome Tool-12 (iHOT$12),{ }^{42}$ and patient- determined satisfaction and pain score (1-10 visual analog scale) preoperatively and at 1 year postoperatively.

To quantify the clinical significance of outcome achievement, we applied the principles of achieving MCID as defined for functional PROMs. Previous work has proposed that MCID be considered a minimum target. ${ }^{43}$ MCID for the HOS-ADL, HOS-SS, mHHS, and iHOT-12 was determined by calculating the $1 / 2$ standard deviation of each PROM mean in the study patients, as described in the literature. ${ }^{44-46}$ When describing achievement of clinically significant outcome, it is generally accepted that this is defined as achievement of MCID on any hip-specific outcome measure. ${ }^{47,48}$ The burden of MCID achievement across all outcome measures may not be realistic, given that each outcome measure may represent a separate outcome domain. As such, patients were considered to have achieved MCID if they achieved the respective outcome end point on at least 1 of the administered questionnaires. ${ }^{49}$ Our methodology here is in line with adopted and accepted

Table 2. TSK-11 Score Averages by Time Points

\begin{tabular}{lc}
\hline & Mean \pm Standard Deviation \\
\hline Preoperative TSK-11 & $26.22 \pm 5.99$ \\
6-month TSK-11 & $19.57 \pm 6.35$ \\
1-year TSK-1 1 & $18.70 \pm 6.49$ \\
\hline
\end{tabular}

TSK-11, Tampa Scale of Kinesiophobia-11. 
Table 3. Post-hoc Analysis of Repeated-Measures Analysis of Variance for the TSK-11

\begin{tabular}{lcccr}
\hline & & & \multicolumn{2}{c}{$95 \%$ Confidence Interval } \\
\cline { 3 - 5 } & Mean Difference* & Std. Error & $P$ Value & Lower Bound \\
\hline TSK-11, 6 mo & 6.3 & 0.73 & $<.001$ & 4.502 \\
TSK-11, 1 y & 7.8 & 0.905 & $<.001$ & 5.572 \\
\hline
\end{tabular}

TSK-11, Tampa Scale of Kinesiophobia-11.

*Indicates mean difference from preoperative score averages.

methods previously reported and supported in the literature. ${ }^{45,49-52}$

\section{Statistical Analysis}

All data were screened to determine whether parametric statistical assumptions were met before analysis. In cases of parametric analysis violation, the nonparametric analogue tests were applied. Paired samples $t$ tests were used to compare preoperative and 1-year postoperative patient-reported outcome scores in patients with FAIS. Independent $t$ tests were used to compare preoperative PCS and TSK score averages between patients achieving 6-month and 1-year MCID thresholds. Repeated-measures analysis of variance (ANOVA) to assess whether PCS and TSK score averages differed over the time points, and post-hoc analysis with a Bonferroni adjustment was performed to determine significant differences within the timepoints.

Descriptive statistics for all continuous variables are reported as mean and standard deviations, and frequency statistics were reported for all noncontinuous variables. Statistical significance for all analysis was set at $P<.05$. All statistical analysis was performed using SPSS, version 25 (IBM Corp., Armonk, NY).

\section{Results}

\section{Demographics}

Of the 124 patients who were enrolled in the study, 108 met inclusion criteria, of whom 85 patients $(80.2 \%)$ had 1 -year functional, TSK, and PCS scores and were included in the final analysis (Fig 1). The patient study group had an average age of $33.94 \pm$ 12.30 years and body mass index of $24.37 \pm 4.05$, with the majority being female $(75.3 \%)$ (Table 1$)$.

\section{Kinesiophobia}

The TSK score averages at the 3 time points recorded are summarized in Table 2. Repeated-measures ANOVA demonstrated TSK score averages were statistically significantly different at the different time points over the course of a year $(\mathrm{F}[1945]=74.3 ; P<.001)$. Post hoc analysis with a Bonferroni adjustment revealed that TSK score averages at all time points were significantly lower form baseline (all $P<.001$ ); however, there was no significant difference between 6 months and 1 year $(P>.05)$ (Table 3$)$.

\section{Pain Catastrophizing}

The PCS score averages at the 3 time points recorded are summarized in Table 4. Repeated-measures ANOVA demonstrated PCS score averages were statistically significantly different at the different time points over the course of a year $(\mathrm{F}[3,337]=72.45 ; P<.001)$. Post hoc analysis with a Bonferroni adjustment revealed that PCS score averages at all time points were significantly lower form baseline $(P<.001$ for all $)$; however, there was no significant difference between 6-month and l-year $(P>.05$ for all) (Table 5).

\section{Clinical Outcomes}

There were significant improvements in all PROMs as well as in pain scores following surgery at an average $19.9 \pm 5.6(12-25)$ months. Paired $t$ test analysis of preand 1-year minimum postoperative patient reported outcome score averages for the combined study population are reported in Table 6 . There was a statistically significant increase in HOS-ADL, HOS-SS, and iHOT-12 as well as a significant reduction in reported visual analog scale for pain at 1-year postoperatively.

The calculated HOS-ADL, HOS-SS, mHHS, and iHOT12 threshold scores for achieving MCID at 1 year from surgery were 9.7, 15.7, 9.2, and 13.1, respectively. The percentage of patients achieving MCID for each PROM is detailed in Table 7 . To summarize, most patients achieved the mHHS threshold for mHHS (87.3\%) whereas the lowest percentage of patients achieving any threshold was HOS-SS $(64.6 \%)$. A total of 55 $(87.3 \%)$ of patients achieved at least 1 PROM score threshold for MCID.

\section{TSK and PCS Scores Predictive of Achieving 1-Year MCID}

Receiver operating characteristics curve analysis found that scoring a PCS score of 25.5 and TSK score of 38.5 was predictive of achieving MCID; however, both these number failed to achieve significance $(P>.05)$

Table 4. PCS Score Averages by Time Points

\begin{tabular}{lc}
\hline & Mean \pm Standard Deviation \\
\hline Preoperative PCS Score & $17.81 \pm 10.13$ \\
PCS, 6 mo & $4.64 \pm 6.83$ \\
PCS, 1 y & $4.77 \pm 7.57$ \\
\hline PCS, Pain Catastrophizing Scale.
\end{tabular}


Table 5. Post-hoc Analysis of Repeated Measures Analysis of Variance for PCS

\begin{tabular}{lcccc}
\hline & & & \multicolumn{2}{c}{$95 \%$ Confidence Interval } \\
\cline { 3 - 5 } & Mean Difference & Std. Error & $P$ Value & Lower Bound \\
\hline PCS, 6 mo & 12.23 & 1.259 & $<.001$ & 9.138 \\
PCS, 1 y & 12.77 & 1.468 & $<.001$ & 9.154 \\
\hline
\end{tabular}

PCS, Pain Catastrophizing Scale.

*Indicates mean difference from preoperative score averages

(Fig 2). Independent $t$ test analysis demonstrated that 1-year PCS score averages were statistically different between the patient groups that achieved MCID compared with the group that did not achieve MCID $(3.2 \pm 4.4$ vs $10.8 \pm 15.2 ; P=.006$; Table 8$)$. There was no statistical difference in 1-year TSK, preoperative TSK, or preoperative PCS score averages between the 2 groups.

\section{Discussion}

In this study, we found that PCS and TSK scores show significant declines postoperatively after hip arthroscopy for FAIS, whereas hip-specific PROMs show statistically significant improvement during the same time frame. 1-year PCS scores averages were significantly lower in patients who achieve MCID versus the group that did not (3.2 vs 10.8). TSK scores, however, were not significantly different between patients achieving MCID. This information suggests that PCS may have a useful role in the postoperative rehabilitation strategies for patients undergoing hip arthroscopy for FAIS.

Growing evidence shows that psychological factors such as depression and psychological distress influence the outcome of hip arthroscopy. ${ }^{14-16}$ Psychological distress was shown to be a predictor of worse preoperative PROMs compared with patients who were not distressed as well as a predictor of increased pain in the immediate postoperative period. ${ }^{18,53}$ The specific factors of psychological distress such as kinesiophobia and pain catastrophizing have not been widely studied in the hip arthroscopy literature. With regards to the current study, we found that pain catastrophizing scores at 1 year were significantly different between

Table 6. Comparison of Preoperative and 1-Year Reported Outcomes

\begin{tabular}{lccc}
\hline & $\begin{array}{c}\text { Preoperative Score, } \\
\text { Mean } \pm \text { SD }\end{array}$ & $\begin{array}{c}\text { 1-Year Postoperative, } \\
\text { Mean } \pm \text { SD }\end{array}$ & $P$ Value \\
\hline HOS-ADL & $67.9 \pm 15.2$ & $87.5 \pm 16.9$ & $<.001$ \\
HOS-SS & $43.7 \pm 24.1$ & $73.5 \pm 28.2$ & $<.001$ \\
mHHS & $63.9 \pm 11.1$ & $83.4 \pm 18.9$ & $<.001$ \\
iHOT-12 & $37.7 \pm 16.1$ & $73.9 \pm 26.3$ & $<.001$ \\
VAS Pain & $47.2 \pm 19.3$ & $21.2 \pm 26.0$ & $<.001$ \\
\hline
\end{tabular}

HOS-ADL, Hip Outcome Score with Activities of Daily Living Subscale; HOS-SS, Hip Outcome Score with Sports-Specific Subscale; iHOT-12, International Hip Outcome Tool-12; mHHS, modified Harris Hip Score; SD, standard deviation; VAS, visual analog scale. patients achieving and failing to achieve MCID at l-year follow-up.

It is worth noting there was no significant difference in 1-year TSK-11 scores in these same patients. This finding may be explained by the fact that kinesiophobia is a modifiable risk factor that improves with rehabilitation and surgical intervention. The lack of significant finding for predictive ability of kinesiophobia agrees with Chmielewski et al., ${ }^{32}$ who showed that kinesiophobia is inversely related with functional level following anterior cruciate ligament reconstruction, but only in the time frame when patients were closest to return to sport (i.e., limited relationship). Kinesiophobia can be addressed through physical therapy and neuromuscular retraining. Pain catastrophizing represents a worldview and outlook and as such is likely hardwired and more intrinsic to a patient's psyche. Furthermore, pain catastrophizing may not be modifiable and persistently elevated in patients with a psychological predisposition to pain catastrophizing. The significant finding for the predictive ability of PCS supports work by Kim et al., ${ }^{26}$ who showed that PCS scores after lumbar spinal surgeries were correlated with outcomes at the time point in which the questionnaire was administered. As such, we believe that the postoperative PCS scores may serve as a better postoperative evaluation tool to identify patients at risk for not achieving clinically significant outcome after hip arthroscopy for FAIS.

The current study demonstrates the close relationship between psychological distress and physical dysfunction. Patient-reported functional scores are by their very nature are subjective reporting. Our theory is that

Table 7. Comparison of Number of Patients Achieving 1-Year MCID Thresholds

\begin{tabular}{lc}
\hline & 1 -Year MCID \\
\hline HOS-ADL & $46(72.2 \%)$ \\
HOS-SS & $31(64.6 \%)$ \\
mHHS & $55(87.3 \%)$ \\
iHOT-12 & $41(77.4 \%)$ \\
Any MCID & $55(87.3 \%)$ \\
\hline
\end{tabular}

HOS-ADL, Hip Outcome Score with Activities of Daily Living Subscale; HOS-SS, Hip Outcome Score with Sports-Specific Subscale; iHOT-12, International Hip Outcome Tool-12; MCID, minimal clinically important difference; mHHS, modified Harris Hip Score. 


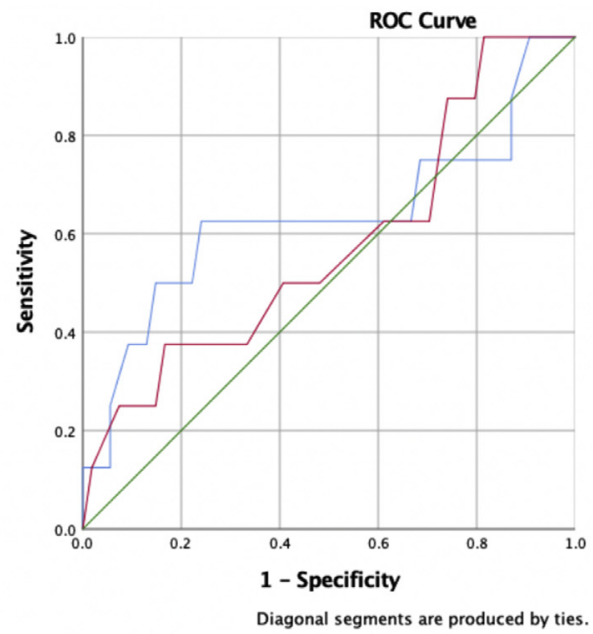

Diagonal segments are produced by ties.

\begin{tabular}{lccccc} 
& & & \multicolumn{2}{c}{$\begin{array}{c}\text { Asymptotic } 95 \% \text { Confidence } \\
\text { Interval }\end{array}$} \\
& Area Under the Curve & Standard Error & P-value & Lower Bound & Upper Bound \\
\cline { 2 - 6 } Preoperative PCS & 0.633 & 0.129 & 0.227 & 0.38 & 0.886 \\
Preoperative TSK & 0.578 & 0.114 & 0.482 & 0.355 & 0.801
\end{tabular}

Fig 2. ROC curve analysis of preoperative TSK-11 and PCS scores predictive of achieving 1-year minimal clinically important difference. (PCS, Pain Catastrophizing Scale; ROC, receiver operating characteristic; TSK-11, Tampa Scale for Kinesiophobia-11.) patients with psychological distress are less likely to perceive functional improvements in the way that nondistressed patients are. Although the presence of kinesiophobia and pain catastrophizing are not an absolute contraindication to surgery, they undeniably can affect outcomes. We found that pain catastrophizing has an effect on achieving MCID at the specific time point patients experience this psychological factor, but both pain catastrophizing and kinesiophobia were not predictive of future outcomes. The receiver operating characteristic analysis that examined preoperative PCS and TSK-11 scores revealed a score 25.5 and 38.5, respectively, were predictive of patients achieving MCID at 1-year follow-up. Although these values did not reach significance, they may serve as a guide to determine whether patients are at risk of not achieving MCID. However, further research is required to evaluate the predictive value of the PCS and TSK-11.

There are a number of strengths in this study. Based on the results, reduction of pain catastrophizing should be prioritized, as it is correlated with achieving MCID. Another strength of this study is that pain catastrophizing and kinesiophobia were both evaluated using validated scoring tools in patients who underwent hip arthroscopy for FAIS. As such, the PCS scoring tool may be used to objectively identify pain catastrophizing that may intervene with successful postsurgical recovery.

\section{Limitations}

Several limitations are present in this study that should be addressed. First, this study had a relatively short follow-up of a minimum of 1 year. Second, although patients were prospectively enrolled, some refused to answer the questionnaires, and some were lost to follow-up. Third, strict inclusion and exclusion criteria were used for the patients analyzed in this study, which may have introduced selection bias. Fourth, multiple factors other than kinesiophobia and pain catastrophizing can affect patient reported outcomes following hip arthroscopy. Fifth, an a-priori power analysis was not performed, so the analysis may be underpowered. Lastly, all of the surgical procedures were performed by a single high-volume, fellowshiptrained surgeon, with extensive experience in hip arthroscopy and the outcomes of this study may not be generalizable.

Table 8. Comparison of PCS and TSK-11 Score Averages in Patients Who Achieved and Did Not Achieve l-Year MCID

\begin{tabular}{lccc}
\hline & Achieved Any 1-Year MCID & Not Achieved Any l-Year MCID & $P$ Value \\
\hline Preoperative PCS & $16.5 \pm 9.7$ & $22.0 \pm 13.8$ & .159 \\
PCS, 1 y & $3.2 \pm 4.4$ & $10.8 \pm 15.2$ & .006 \\
Preoperative TSK-11 & $25.7 \pm 6.0$ & $28.4 \pm 6.9$ & .255 \\
TSK-11, 1 y & $18.1 \pm 5.6$ & $21.5 \pm 12.3$ & .229 \\
\hline
\end{tabular}

MCID, minimal clinically important difference; PCS, Pain Catastrophizing Scale; TSK-11, Tampa Scale for Kinesiophiobia-11. 


\section{Conclusions}

Patient kinesiophobia and pain catastrophizing both show significant improvements 1 year after undergoing hip arthroscopy for FAIS. However, pain catastrophizing scores at 1 year are significantly greater in patients not achieving MCID, whereas no association was identified between kinesiophobia and likelihood for MCID achievement. This suggests PCS may be a more useful tool than TSK-1l for during postoperative rehabilitation for identifying patients at risk for not achieving MCID.

\section{References}

1. Bonazza NA, Homcha B, Liu G, Leslie DL, Dhawan A. Surgical trends in arthroscopic hip surgery using a large national database. Arthroscopy 2018;34:1825-1830.

2. Domb BG, Martin TJ, Gui C, Chandrasekaran S, SuarezAhedo C, Lodhia P. Predictors of clinical outcomes after hip arthroscopy: A prospective analysis of 1038 patients with 2-year follow-up. Am J Sports Med 2018;46: 1324-1330.

3. Griffin DR, Dickenson EJ, Wall PDH, et al. Hip arthroscopy versus best conservative care for the treatment of femoroacetabular impingement syndrome (UK FASHIoN): A multicentre randomised controlled trial. Lancet 2018;391:2225-2235.

4. Alradwan H, Philippon MJ, Farrokhyar F, et al. Return to preinjury activity levels after surgical management of femoroacetabular impingement in athletes. Arthroscopy 2012;28:1567-1576.

5. Byrd JW, Jones KS. Hip arthroscopy in athletes: 10-year follow-up. Am J Sports Med 2009;37:2140-2143.

6. Weber AE, Kuhns BD, Cvetanovich GL, Grzybowski JS, Salata MJ, Nho SJ. Amateur and recreational athletes return to sport at a high rate following hip arthroscopy for femoroacetabular impingement. Arthroscopy 2017;33: 748-755.

7. Kunze KN, Leong NL, Beck EC, Bush-Joseph CA, Nho SJ. Hip Arthroscopy for femoroacetabular impingement improves sleep quality postoperatively. Arthroscopy 2019;35: 461-469.

8. Menge TJ, Briggs KK, Dornan GJ, McNamara SC, Philippon MJ. Survivorship and outcomes 10 years following hip arthroscopy for femoroacetabular impingement: Labral debridement compared with labral repair. J Bone Joint Surg Am 2017;99:997-1004.

9. Byrd JW, Jones KS. Prospective analysis of hip arthroscopy with 10-year followup. Clin Orthop Rel Res 2010;468: 741-746.

10. Frank RM, Lee S, Bush-Joseph CA, Salata MJ, Mather RC 3rd, Nho SJ. Outcomes for hip arthroscopy according to sex and age: A comparative matched-group analysis. J Bone Joint Surg Am 2016;98:797-804.

11. Perets I, Rybalko D, Chaharbakhshi EO, Mu BH, Chen AW, Domb BG. Minimum five-year outcomes of hip arthroscopy for the treatment of femoroacetabular impingement and labral tears in patients with obesity: A match-controlled study. J Bone Joint Surg Am 2018;100: 965-973.
12. Ayers DC, Franklin PD, Ring DC. The role of emotional health in functional outcomes after orthopaedic surgery: Extending the biopsychosocial model to orthopaedics: AOA critical issues. J Bone Joint Surg Am 2013;95:e165.

13. Flanigan DC EJ, Glassman AH. Psychological factors affecting rehabilitation and outcomes following elective orthopaedic surgery. J Am Acad Orthop Surg 2015;23: 563-570.

14. Sochacki KR, Brown L, Cenkus K, Di Stasi S, Harris JD, Ellis TJ. Preoperative depression is negatively associated with function and predicts poorer outcomes after hip arthroscopy for femoroacetabular impingement. Arthroscopy 2018;34:2368-2374.

15. Lansdown DA, Ukwuani G, Kuhns B, Harris JD, Nho SJ. Self-reported mental disorders negatively influence surgical outcomes after arthroscopic treatment of femoroacetabular impingement. Orthop J Sports Med 2018;6: 2325967118773312.

16. Martin RL, Christoforetti JJ, McGovern R, et al. The impact of depression on patient outcomes in hip arthroscopic surgery. Orthop J Sports Med 2018;6: 2325967118806490.

17. Stone AV, Malloy P, Beck EC, et al. Predictors of persistent postoperative pain at minimum 2 years after arthroscopic treatment of femoroacetabular impingement. Am J Sports Med 2019;47:552-559.

18. Potter MQ, Wylie JD, Sun GS, Beckmann JT, Aoki SK. Psychologic distress reduces preoperative self-assessment scores in femoroacetabular impingement patients. Clin Orthop Relat Res 2014;472:1886-1892.

19. Filardo G, Roffi A, Merli G, et al. Patient kinesiophobia affects both recovery time and final outcome after total knee arthroplasty. Knee Surg Sports Traumatol Arthrose 2016;24:3322-3328.

20. Domenech J, Sanchis-Alfonso V, Lopez L, Espejo B. Influence of kinesiophobia and catastrophizing on pain and disability in anterior knee pain patients. Knee Surg Sports Traumatol Arthrosc 2013;21:1562-1568.

21. Leeuw M, Goossens ME, Linton SJ, Crombez G, Boersma K, Vlaeyen JW. The fear-avoidance model of musculoskeletal pain: current state of scientific evidence. J Behav Med 2007;30:77-94.

22. Sullivan MJL, Bishop SR, Pivik J. The Pain Catastrophizing Scale-Development and validation. Psychological Assessment 1995;7:524-532.

23. Woby SR, Roach NK, Urmston M, Watson PJ. Psychometric properties of the TSK-11: A shortened version of the Tampa Scale for Kinesiophobia. Pain 2005;117: 137-144.

24. Sullivan M, Tanzer M, Reardon G, Amirault D, Dunbar M, Stanish W. The role of presurgical expectancies in predicting pain and function one year following total knee arthroplasty. Pain 2011 1; 52:2287-2293.

25. Riddle DL, Wade JB, Jiranek WA, Kong X. Preoperative pain catastrophizing predicts pain outcome after knee arthroplasty. Clin Orthop Relat Res 2010;468: 798-806.

26. Kim HJ, Kwon OH, Chang BS, Lee CK, Chun HJ, Yeom JS. Change in pain catastrophizing in patients with lumbar spinal surgery. Spine J 2018;18:115-121. 
27. Kocic M, Stankovic A, Lazovic M, et al. Influence of fear of movement on total knee arthroplasty outcome. Ann Ital Chir 2015;86:148-155.

28. Archer KR, Seebach CL, Mathis SL, Riley LH 3rd, Wegener ST. Early postoperative fear of movement predicts pain, disability, and physical health six months after spinal surgery for degenerative conditions. Spine $J$ 2014; 14:759-767.

29. Lentz TA, Zeppieri G Jr, Tillman SM, et al. Return to preinjury sports participation following anterior cruciate ligament reconstruction: Contributions of demographic, knee impairment, and self-report measures. J Orthop Sports Phys Ther 2012;42:893-901.

30. Kvist J, Ek A, Sporrstedt K, Good L. Fear of re-injury: A hindrance for returning to sports after anterior cruciate ligament reconstruction. Knee Surg Sports Traumatol Arthrosc 2005;13:393-397.

31. Malloy P, Gray K, Wolff AB. Rehabilitation after hip arthroscopy: A movement control-based perspective. Clin Sports Med 2016;35:503-521.

32. Chmielewski TL, Jones D, Day T, Tillman SM, Lentz TA, George SZ. The association of pain and fear of movement/ reinjury with function during anterior cruciate ligament reconstruction rehabilitation. J Orthop Sports Phys Ther 2008;38:746-753.

33. Griffin DR, Dickenson EJ, O'Donnell J, et al. The Warwick Agreement on femoroacetabular impingement syndrome (FAI syndrome): An international consensus statement. Br J Sports Med 2016;50:1169-1176.

34. Clohisy JC, Carlisle JC, Beaule PE, et al. A systematic approach to the plain radiographic evaluation of the young adult hip. J Bone Joint Surg Am 2008;90:47-66 (suppl 4).

35. Frank RM, Lee S, Bush-Joseph CA, Kelly BT, Salata MJ, Nho SJ. Improved outcomes after hip arthroscopic surgery in patients undergoing $\mathrm{T}$-capsulotomy with complete repair versus partial repair for femoroacetabular impingement: A comparative matched-pair analysis. Am J Sports Med 2014;42:2634-2642.

36. Slikker W 3rd, Van Thiel GS, Chahal J, Nho SJ. The use of double-loaded suture anchors for labral repair and capsular repair during hip arthroscopy. Arthrosc Tech 2012;1:e213-e217.

37. Harris JD, Slikker W 3rd, Gupta AK, McCormick FM, Nho SJ. Routine complete capsular closure during hip arthroscopy. Arthrosc Tech 2013;2:e89-e94.

38. Nho SJ, Beck EC, Kunze KN, Okoroha K, Suppauksorn S. Contemporary management of the hip capsule during arthroscopic hip preservation surgery. Curr Rev Musculoskelet Med 2019:260-270.

39. Martin RL, Kelly BT, Philippon MJ. Evidence of validity for the hip outcome score. Arthroscopy 2006;22: 1304-1311.

40. Martin RL, Philippon MJ. Evidence of reliability and responsiveness for the hip outcome score. Arthroscopy 2008;24:676-682.
41. Chahal J, Van Thiel GS, Mather RC 3rd, et al. The patient acceptable symptomatic state for the Modified Harris Hip Score and Hip Outcome Score among patients undergoing surgical treatment for femoroacetabular impingement. Am J Sports Med 2015;43:1844-1849.

42. Griffin DR, Parsons N, Mohtadi NG, Safran MR. A short version of the International Hip Outcome Tool (iHOT-12) for use in routine clinical practice. Arthroscopy 2012;28: 611-616. quiz 616-618.

43. Nwachukwu BU, Chang B, Adjei J, et al. Time required to achieve minimal clinically important difference and substantial clinical benefit after arthroscopic treatment of femoroacetabular impingement. Am J Sports Med 2018;46: 2601-2606.

44. Martin RL, Kivlan BR, Christoforetti JJ, et al. Minimal clinically important difference and substantial clinical benefit values for a pain visual analog scale after hip arthroscopy. Arthroscopy 2019;35:2064-2069.

45. Beck EC, Nwachukwu BU, Kunze KN, Chahla J, Nho SJ. How can we define clinically important improvement in pain scores after hip arthroscopy for femoroacetabular impingement syndrome? Minimum 2-year follow-up study. Am J Sports Med 2019;47:3133-3140.

46. Nwachukwu BU, Chang B, Beck EC, et al. How should we define clinically significant outcome improvement on the iHOT-12? HSS J 2019;15:103-108.

47. Nwachukwu BU. Editorial Commentary: PASSing the test versus acing it: Understanding clinically significant outcome improvement in arthroscopic hip surgery. Arthroscopy 2019;35:1463-1465.

48. Bernstein DN, Nwachukwu BU, Bozic KJ. Value-based health care: Moving beyond "minimum clinically important difference" to a tiered system of evaluating successful clinical outcomes. Clin Orthop Relat Res 2019;477:945-947.

49. Beck EC, Nwachukwu BU, Chahla J, et al. Patients with borderline hip dysplasia achieve clinically significant outcome after arthroscopic femoroacetabular impingement surgery: A case-control study with minimum 2-year follow-up. Am J Sports Med 2019;47:2636-2645.

50. Chahla J, Beck EC, Okoroha K, Cancienne JM, Kunze KN, Nho SJ. Prevalence and clinical implications of chondral injuries after hip arthroscopic surgery for femoroacetabular impingement syndrome. Am J Sports Med 2019;47:2626-2635.

51. Okoroha KR, Beck EC, Nwachukwu BU, Kunze KN, Nho SJ. Defining minimal clinically important difference and patient acceptable symptom state after isolated endoscopic gluteus medius repair. Am J Sports Med 2019;47:3141-3147.

52. Stone AV, Beck EC, Malloy P, et al. Preoperative predictors of achieving clinically significant athletic functional status after hip arthroscopy for femoroacetabular impingement at minimum 2-year follow-up. Arthroscopy 2019;35:3049-3056 e3041.

53. Potter MQ, Sun GS, Fraser JA, et al. Psychological distress in hip arthroscopy patients affects postoperative pain control. Arthroscopy 2014;30:195-201. 